\title{
Drowning induced acute respiratory failure: A case report
}

\author{
Soumaya Touzani, Nawfal Houari, Abderrahim Elbouazzaoui, \\ Brahim Boukatta, Nabil Kanjaa
}

\begin{abstract}
Introduction: Drowning is still a relevant medical challenge and a leading cause of accidental death worldwide. Hypoxia is the starting point for all morbidity and mortality and it must remain the focus of treatment. Case Report: We report the case of non-fatal drowning in an epileptic patient who presented to the emergency department with acute respiratory failure (ARF) and subsequent neurological status impairment. The patient's condition was managed with early noninvasive ventilation (NIV). He was rapidly discharged from ICU despite severe hypoxemia on admission. Although the applications of NIV have been increased recently in the emergency settings, reports about its efficiency in drowning ARF are limited. Conclusion: Early administration of non-invasive ventilation would be interesting to manage drowning induced ARF through positive expiratory pressure while avoiding complications related to conventional ventilation.
\end{abstract}

Touzani Soumaya ${ }^{1}$, Houari Nawfal ${ }^{1}$, Elbouazzaoui Abderrahim $^{2}$, Boukatta Brahim², Kanjaa Nabil ${ }^{3}$

Affiliations: ${ }^{1}$ Assistant Professor, Department of Anesthesiology and Intensive Care A4, University Hospital Hassan II, Fez, Morocco; ${ }^{2}$ Associate Professor, Department of Anesthesiology and Intensive Care A4, University Hospital Hassan II, Fez, Morocco; ${ }^{3} \mathrm{Head}$ of Department, Department of Anesthesiology and Intensive Care A4, University Hospital Hassan II, Fez, Morocco.

Corresponding Author: Soumaya Touzani, Department of Anesthesiology and Intensive Care A4, University Hospital Hassan II, SidiHrazem Road, FEZ, Morocco, 30070; E-mail: touzani.soumaya@gmail.com

Received: 17 June 2018

Accepted: 02 July 2018

Published: 23 July 2018
Keywords: Acute respiratory distress syndrome, Acute respiratory failure, Drowning, Non-invasive ventilation

\section{How to cite this article}

Touzani S, Houari N, Elbouazzaoui A, Boukatta B, Kanjaa N. Drowning induced acute respiratory failure: A case report. Int $\mathrm{J}$ Case Rep Images 2018;9:100939Z01ST2018.

Article ID: 100939Zo1ST2018

$* * * * * * * * *$

doi: 10.5348/100939Z01ST2018CR

\section{INTRODUCTION}

Drowning is still one of the leading causes of accidental death worldwide. More than 500 ooo deaths occur each year after unintentional drowning according to the World Health Organization (WHO) [1]. Acute respiratory failure (ARF) is the main component of drowning physiopathology. The end result of drowning is surfactant dysfunction, pulmonary edema, a decrease in pulmonary compliance and an increase in the ventilation/perfusion mismatch, frequently leading to profound hypoxia and acute respiratory distress syndrome (ARDS) and ultimately causing cardiovascular collapse and death [1]. This condition is still considered as a relevant medical challenge as clinical data are still lacking on the best medical strategy to use. The practice of non-invasive ventilation (NIV) has been increased recently in emergency settings [2], but its safety and efficiency in drowning related ARF remains unknown. This case report highlights the successful management of non-fatal drowning related ARF with early non-invasive ventilation. 


\section{EDORIUM Journals}

\section{CASE REPORT}

A 46-year-old man, with history of epilepsy and mental retardation, was brought to the emergency department (ED) after submersion in a thermal pool while sitting at the edge. No prior epileptic seizure was reported by his accompanying family member. Bystanders reported that the patient was submerged for approximately 1 minute. When rescued, he was unconscious and polypneic. The transport to hospital was immediate with no medical assistance. On admission to the ED, the physical examination revealed a Glasgow Coma Scale (GCS) score of 13/15 (E3, V4, M5), a pulse rate at 107 beats/min and blood pressure at $150 / 80 \mathrm{mmHg}$. Respiration was spontaneous at 29 breaths/min, with oxygen saturation $\left(\mathrm{SpO}_{2}\right)$ on room air of $60 \%$. He had bilateral crackles on auscultation of the lungs. He was hypothermic at $36.5^{\circ}$ C. Electrocardiogram showed sinusal tachycardia. There was no evidence of trauma. Capillary blood glucose was $1.3 \mathrm{~g} / \mathrm{dl}$. Initial management included: a semi-sitting position, vascular access, warming and high flow of oxygen (10 l/min) through high concentration facial mask. The chest X-ray showed diffused alveolar opacities suggestive of pulmonary edema (Figure 1A). Chest CT scan disclosed multiple bilateral condensation areas and "ground glass" opacifications, consistent with respiratory distress syndrome (Figure 1B). An unenhanced computed tomography (CT) of the brain was unremarkable. His serum creatinine, electrolyte values, blood cell counts and rhabdomyolysis profile were normal. Arterial blood gas analysis (Table 1) revealed a severe hypoxemia (Ratio $\mathrm{PaO}_{2} / \mathrm{FiO}_{2}=110$ ) with compensated respiratory alkalosis $\left(\mathrm{PaCO}_{2}=34, \mathrm{HCO}_{3}^{-}=22, \mathrm{pH}=7.41\right)$ and hyperlactatemia at $2.5 \mathrm{mmol} / \mathrm{l}$ ( Normal $<2 \mathrm{mmol} / \mathrm{l}$ ). Non invasive ventilation (NIV) was immediately started in the ED, even before the CT chest and brain, and continued upon admission to the Intensive Care Unit (ICU).The head of the bed was elevated to $30^{\circ}$ during ventilation to minimize the risk of aspiration. No sedation was needed. Non-invasive positive pressure ventilation on bi-level positive airway pressure (BiPAP) mode was applied via oronasal mask to the patient. Initial ventilator settings included: pressure support $(\mathrm{PS})=12 \mathrm{cmH}_{2} \mathrm{O}$; positive end-expiratory pressure $\left(\right.$ PEEP) $=5 \mathrm{cmH}_{2}^{2} \mathrm{O} ; \mathrm{FiO}_{2} 50 \%$. The pressure support was adjusted to maintain a tidal volume of 6-8 ml/kg. The PEEP and $\mathrm{FiO}_{2}$ were adjusted (gradually increased or decreased in increments of respectively 2 $\mathrm{cmH}_{2} \mathrm{O}$ and $5 \%$ ) to maintain blood oxygen saturation $\left(\mathrm{SpO}_{2}^{2}\right) \geq 90 \%$ or $\mathrm{PaO}_{2} \geq 60 \mathrm{mmHg}$. The vital signs of the patients (neurological status, $\mathrm{SpO}_{2}$, hemodynamic parameters) were closely monitored at all times during the procedure. Invasive hemodynamic monitoring was not required and no remarkable echocardiographic findings were associated with either the respiratory failure or the assisted ventilation (especially no right ventricular dysfunction). Vital signs were stable over the successive 24 hours with progressive improvement of consciousness and progressive resolution of acute respiratory failure
(Table 1). NIV was gradually stopped and replaced by low flow oxygen therapy through nasal cannula before complete weaning. The radiological infiltrate detected on admission gradually improved in the subsequent chest $\mathrm{X}$-rays performed (Figure 2). The patient was discharged from ICU on day 3.

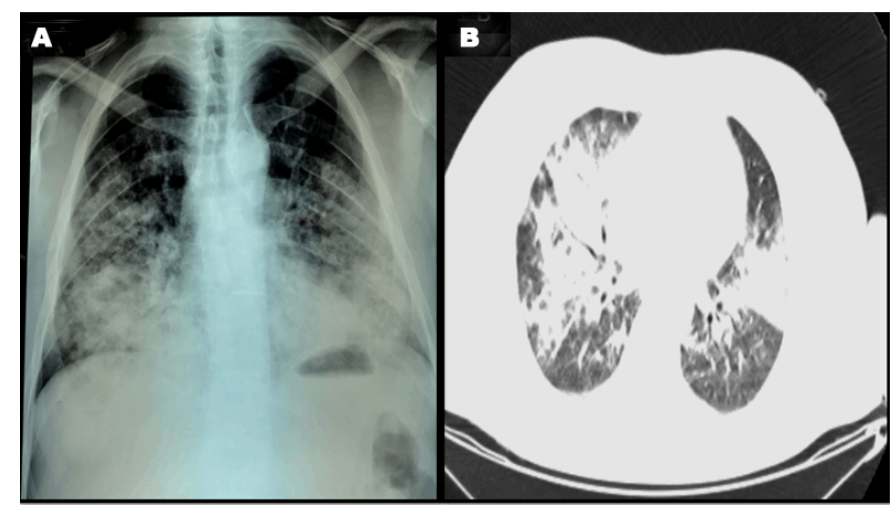

Figure 1: (A) Diffused alveolar opacities on admission chest X-ray (B) Bilateral condensation/ground glass opacifications on admission chest computed tomography.

Table 1: Improving parameters of patient with non-invasive ventilation (NIV) in the 24 hours after admission

\begin{tabular}{|c|c|c|c|c|}
\hline & Admission & $\begin{array}{l}4 \text { hours } \\
\text { NIV }\end{array}$ & $\begin{array}{c}12 \\
\text { hours } \\
\text { NIV }\end{array}$ & $\begin{array}{c}24 \text { hours } \\
\text { NIV }\end{array}$ \\
\hline Ratio & & & & \\
\hline $\begin{array}{l}\mathrm{PaO}_{2} / \\
\mathrm{FiO}_{2}\end{array}$ & 110 & 186 & 205 & 303 \\
\hline $\mathrm{pH}$ & $7 \cdot 41$ & $7 \cdot 44$ & $7 \cdot 41$ & 7.42 \\
\hline $\mathrm{PaCO}_{2}$ & 34 & 33 & 38.4 & 38 \\
\hline $\mathrm{HCO}_{3}^{-}$ & 22 & 22 & 24 & $24 \cdot 5$ \\
\hline GCS & 13 & 13 & 14 & 15 \\
\hline Lactate & 2.5 & & & 0.85 \\
\hline $\begin{array}{l}\text { Szpilman } \\
\text { clinical } \\
\text { score }\end{array}$ & Grade 3 & & & \\
\hline
\end{tabular}

Abbreviations: NIV: Non Invasive Ventilation; $\mathrm{PaO}_{2}$ : partial pressure of oxygen in arterial blood; $\mathrm{FiO}_{2}$ : Fractioned inspired oxygen; $\mathrm{PaCO}_{2}$ : partial pressure of carbon dioxide in arterial blood; $\mathrm{HCO}_{3}^{-}$: Bicarbonate; GCS: Glasgow Coma Score.

\section{DISCUSSION}

The WHO defined drowning as the process of experiencing respiratory impairment from submersion/ immersion in liquid. Non-fatal drowning defines the rescued victims [3]. Drowning is a leading cause of 


\section{EDORIUM Journals}

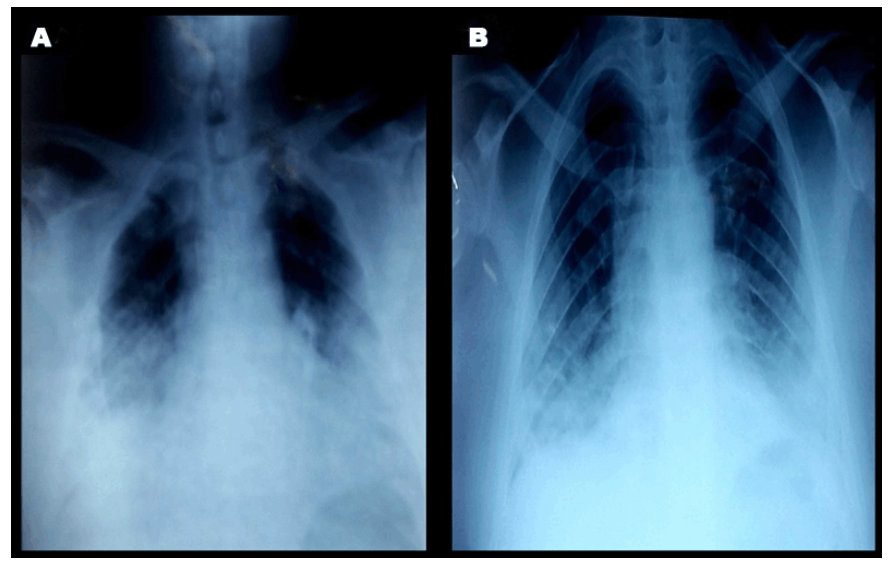

Figure 2: Radiological improvements attested by the decrease of alveolar opacities on day 2 (2A) and day 3 (2B) chest X-rays.

death with over $90 \%$ of cases occurring in lower- and middle-income countries. Toddlers, elderly and those with medical conditions that cause consciousness loss, including epilepsy, are at greatest risk of death by drowning [4, 5]. Hypoxia is the starting point for all morbidity and mortality and it must remain the focus of treatment. Unexpected submersion triggers breathholding and a struggle to surface. Reflex inspiratory efforts lead to hypoxemia by either laryngospasm or aspiration. The quantity of fluid aspirated, rather than the composition, determines subsequent pulmonary derangement. Aspiration of $1-3 \mathrm{ml} / \mathrm{kg}$ body weight of either salt or fresh water compromises the integrity of pulmonary surfactant leading to: alveolar collapse, atelectasis, noncardiogenic pulmonary edema, intrapulmonary shunting and ventilation-perfusion mismatch $(\mathrm{V} / \mathrm{Q})$, resulting in acute respiratory distress syndrome (ARDS). Profound hypoxia and metabolic and respiratory acidoses lead to cardiovascular collapse, neurologic damage and ultimately death [6]. Pulmonary compromise can develop insidiously or rapidly. Signs and symptoms usually include tachypnea, shortness of breath, hypoxia, crackles, which were present in our patient initially. The management and clinical severity of victims are adjusted according to Szpilman scoring system. High-flow $\mathrm{O}_{2}$ or early endotracheal intubation (ETI) are the recommended practices for patients with pulmonary edema (grade 3 or 4). In patients with severe ARDS, ETI and lung protective ventilation with positive end-expiratory pressure should be considered as first option ventilation [1]. The practice of non-invasive ventilation (NIV) has recently increased in the ED with the leading advantage of avoiding pneumonia and other complications associated with endotracheal intubation. The classical indications are acute bronchiolitis and cardiogenic pulmonary edema. The use of non-invasive positive pressure ventilation such as continuous positive airway pressure (CPAP) / bilevel positive airway pressure (BiPAP) in ARDS still controversial [2]. Many studies concluded that use of NIV may be safe in selected patients who are observed carefully [7]. Furthermore,pulmonary edema in drowning cases recovers faster and NIV could be a successful treatment [6]. Non-invasive ventilation can improve respiratory distress through: decreasing the work of breathing, reversing hypoventilation, increasing functional residual capacity, maintaining upper airway patency, recruitment of atelectatic regions and reducing $\mathrm{V} / \mathrm{Q}$ mismatch. A beneficial effect of positive end expiratory pressure (PEEP) has indeed been reported in rare animal studies [8]. The favorable effect of early administration of PEEP has not been clinically demonstrated but is regularly discussed in few case reports and retrospective studies [9-14]. Further prospective evaluation on ventilator supports (NIV, high-flow oxygen device) is needed. To our knowledge, Michelet and al. were the first to report, in a large cohort of drowning related ARF, the effectiveness of NIV. The positive results of NIV in their cases were associated with a stable and/or a rapid improvement of neurological status [13]. Thus, the neurological status and the risk of aspiration should be considered and ETI and mechanical ventilation must not be delayed when the NIV is insufficient. Pneumonia complicating drowning can be fatal. According to Van Berkel et al., intubation is a major risk factor (risk of pneumonia was $52 \%$ in intubated vs. $3 \%$ in non-intubated patients) and therefore the use of NIV appears even more interesting. Systematic antibiotic prophylaxis is reserved for cases of severe aspiration or drowning in heavily contaminated water [15]. In our case, ARF was characterized by a profound but reversal hypoxemia without relevant hypercapnia. Alteration of consciousness related to hypothermia was limited as the thermal water temperature was between 35 and $38^{\circ} \mathrm{C}$. In our alert patient who was breathing spontaneously, NIV was beneficial resulting in recruitment of atelectatic regions and reducing shunt. The clinical and radiological improvement was observed in the first 24 hours despite the initial severe ARF.

\section{CONCLUSION}

Drowning induced acute respiratory failure is frequent condition that can be fatal. Early administration of non-invasive ventilation, associated with a stable and/ or a rapid improvement of neurological status, proved to be interesting on the basis of the use of positive end expiratory pressure (PEEP) while avoiding more severe complications related to conventional ventilation.

\section{REFERENCES}

1. Szpilman D, Bierens JJ, Handley AJ, Orlowski JP. Drowning. N Engl J Med 2012 May 31;366(22):210210.

2. Boldrini R, Fasano L, Nava S. Noninvasive mechanical ventilation. Curr Opin Crit Care 2012 Feb;18(1):4853 . 


\section{EDORIUM Journals}

3. van Beeck EF, Branche CM, Szpilman D, Modell JH, Bierens JJ. A new definition of drowning: Towards documentation and prevention of a global public health problem. Bull World Health Organ 2005 Nov;83(11):853-6.

4. World Health Organization. Global Report on Drowning: Preventing a Leading Killer. Geneva, Switzerland: World Health Organization; 2014.

5. Bell GS, Gaitatzis A, Bell CL, Johnson AL, Sander JW. Drowning in people with epilepsy: How great is the risk? Neurology 2008 Aug 19;71(8):578-82.

6. Buggia M, Canham L, Tibbles C, Landry A. Near drowning and adult respiratory distress syndrome. J Emerg Med 2014 Jun;46(6):821-5.

7. Joshi N, Estes MK, Shipley K, Lee HD. Noninvasive ventilation for patients in acute respiratory distress: An update. Emerg Med Pract 2017 Feb;19(2):1-20.

8. Ruiz BC, Calderwood HW, Modell JH, Brogdon JE. Effect of ventilatory patterns on arterial oxygenation after near-drowning with fresh water: A comparative study in dogs. Anesth Analg 1973 Jul-Aug;52(4):570-6.

9. Dottorini M, Eslami A, Baglioni S, Fiorenzano G, Todisco T. Nasal-continuous positive airway pressure in the treatment of near-drowning in freshwater. Chest 1996 Oct;110(4):1122-4.

10. Gregorakos L, Markou N, Psalida V, et al. Neardrowning: Clinical course of lung injury in adults. Lung 2009 Mar-Apr;187(2):93-7.

11. Brahmi N, Ajmi S, Ben Mokhtar H, Koraichi N, Tabhet $\mathrm{H}$, Amamou M. Intérêt de la ventilation non-invasive au cours des noyades. Abstract du congrès de la SRLF 2003, Réanimation 2002;11(3):SP 29.

12. Ruggeri P, Calcaterra S, Bottari A, Girbino G, Fodale V. Successful management of acute respiratory failure with noninvasive mechanical ventilation after drowning, in an epileptic-patient. Respir Med Case Rep 2016 Feb 21;17:90-2.

13. Michelet P, Bouzana F, Charmensat O, et al. Acute respiratory failure after drowning: A retrospective multicenter survey. Eur J Emerg Med 2017 Aug;24(4):295-300.

14. Çaglar A, Er A, Özden Ö, et al. Efficacy of early non-invasive ventilation in three cases of non-fatal drowning with pulmonary edema in the paediatric emergency department. Hong Kong Journal of Emergency Medicine 2017;23(2):42-6.

15. van Berkel M, Bierens JJ, Lie RL, et al. Pulmonary oedema, pneumonia and mortality in submersion victims; a retrospective study in 125 patients. Intensive Care Med 1996 Feb;22(2):101-7.

\section{Author Contributions}

Soumaya Touzani - Substantial contributions to conception and design, Acquisition of data, Analysis and interpretation of data, Drafting the article, Revising it critically for important intellectual content, Final approval of the version to be published

Nawfal Houari - Substantial contributions to conception and design, Revising it critically for important intellectual content, Final approval of the version to be published Abderrahim Elbouazzaoui - Analysis and interpretation of data, Revising it critically for important intellectual content, Final approval of the version to be published Brahim Boukatta - Analysis and interpretation of data, Revising it critically for important intellectual content, Final approval of the version to be published

Nabil Kanjaa - Analysis and interpretation of data, Revising it critically for important intellectual content, Final approval of the version to be published

\section{Guarantor of Submission}

The corresponding author is the guarantor of submission.

\section{Source of Support}

None

\section{Consent Statement}

Written informed consent was obtained from the patient for publication of this case report.

\section{Conflict of Interest}

Authors declare no conflict of interest.

\section{Copyright}

(C) 2018 Soumaya Touzani et al. This article is distributed under the terms of Creative Commons Attribution License which permits unrestricted use, distribution and reproduction in any medium provided the original author(s) and original publisher are properly credited. Please see the copyright policy on the journal website for more information. 
Access full text article on other devices

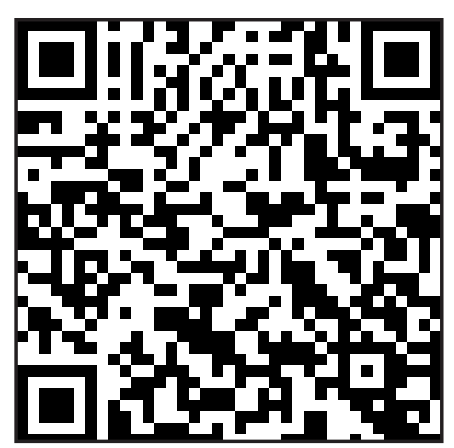

Access PDF of article on other devices

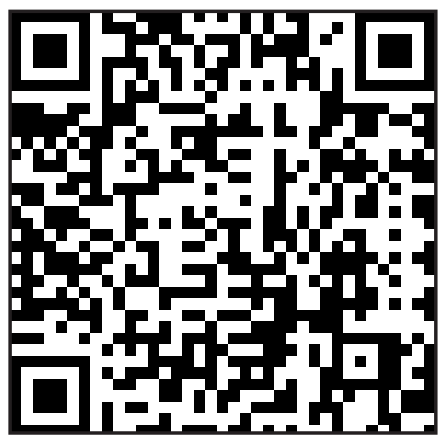

